\title{
Open Access in the Humanities, Arts and Social Sciences: Complex Perceptions of Researchers and Implications for Research Support
}

\section{Niamh Quigley}

School of Media, Creative Arts and Social Inquiry, Curtin University, Perth, Australia

n.quigley@curtin.edu.au, orcid.org/0000-0001-9542-1577

\begin{abstract}
Adoption of open access in the humanities, arts and social sciences (HASS) is a work in progress, with lower engagement in HASS than most of the natural sciences. HASS research impacts how we live, how we learn and how we see ourselves, and research institutions should encourage and enable their HASS research communities to increase the prevalence of open access research outputs. Six experienced HASS researchers at a single academic institution in Perth, Australia, were interviewed to explore their perceptions and experiences of open access, and any barriers that they had encountered. Thematic analysis was used to code the transcribed interviews, and generate themes.This study found a wide variance in the adoption of open access practices among HASS researchers. Some participants are publishing via APC-based gold open access (in DOAJ listed journals), while other participants encounter multiple barriers to sharing more of their work as open access. Confusion about aspects of open access is evident. Even among participants who support open access, some have had poor experiences of open access publishing. This research also found that some participants hold extremely complex opinions on open access, which directly influence participants' behaviour depending on which perspective they are considering. These perspectives are: research supervisor, editorial role at journal, funding assessor and global citizen. Within HASS a diversity of behaviours exists around open access, and research institutions need to tailor their
\end{abstract}

This work is licensed under a Creative Commons Attribution 4.0 International License

Uopen Journals | http://liberquarterly.eu/ | DOI: 10.53377/lq.10937 
research support services around open access and scholarly publishing for different communities of researchers.

Keywords: perceptions of open access; HASS researchers; scholarly communications

\section{Introduction}

The adoption of open access in the humanities, arts and social sciences (HASS) has been lower than in most of the natural sciences (Severin et al., 2020, pp. 7, 14,15$)$, despite the known benefits such as the potential for higher download numbers and higher citations (Piwowar et al., 2018, p. 1). Specific to humanities researchers, many support the idea of open access, but do not all share their work as open access (Eve, 2014, p. 30). Barriers to increasing open access specific to HASS researchers have been noted, such as fears that research would be remixed due to less restrictive licensing in open access (Eve, 2014, p. 32). Some HASS researchers are also confused about the meaning of open access (Creaser et al., 2010, p. 152).

The sharing of research outputs is part of the system of scholarly communication. Open access to research outputs means they can be read by all, rather than just by institutions who can afford to pay journal subscriptions. The impact of paywalled journal articles is that HASS practitioners cannot access the research that is intended for them. For example, education research cannot be fully accessed by teachers, and creative art research cannot be fully accessed by artists. HASS research impacts how we live, how we learn and how we see ourselves, and it is essential for libraries to assist their HASS communities in encouraging, enabling and increasing open access. In Australia, HASS research is funded by the government via the Australian Research Council (Australian Research Council, 2018), as well as institutional and industry funding.

Multiple types of open access exist (Suber, 2012, 2019). Green, gold and diamond open access are defined here, as they are relevant to the experiences of the participants in this research. An institutional repository is a digital archive used to preserve the research outputs of an institution. Green open access is where a peer-reviewed journal article is free to read in an institutional, subject repository or personal website, if permitted by the journal 
publisher. In some cases the journal itself is not open access, and the onus is on the author of a journal article to deposit it in a repository (Suber, 2019). In addition, embargo periods can be applied by journal publishers, where the author must wait before making their journal article available as green open access in a repository (Eve, 2014, pp. 8-9).

Gold open access is where a peer-reviewed journal article is free to read without embargo from the journal publisher. Some gold open access journals are free to publish, while others require payment of an Article Processing Charge (APC) (Suber, 2019). The APC can be paid by the author, institution, library or research funder (Suber, 2012). In this article, gold open access journals where payment is required to publish will be referred to as APC-based gold. Diamond journals do not charge to publish or read peer-reviewed articles, and are generally 'collaborative [and] community-driven' (Bosman et al., 2021, p. 6). Hybrid open access is where a fee is paid to publish an open access journal article in a subscription journal.

At Curtin University, in Perth, Australia, the Faculty of Humanities has three schools: the School of Design and the Built Environment; the School of Education; and the School of Media, Creative Arts and Social Inquiry (MCASI). The research within the Faculty of Humanities spans across the humanities, arts and social sciences. In 2020, Curtin University Library recognised the need to provide better support for their community of HASS researchers, and engaged a Master of Information Management student to carry out a research project. Library staff collaborated with this author on the research questions and the interview guide, and this article presents some of the findings of this research project.

\subsection{Research Questions}

This study sets out to explore HASS researchers' perceptions and experiences of open access, and the barriers they faced in making more of their research outputs available as open access. The research questions from the study relevant to this article are:

1. What are the perceptions and experiences among HASS researchers of publishing journal articles as open access? 
2. What are the barriers preventing HASS researchers from publishing their journal articles as open access?

Purposive sampling was used to recruit two participants from each of three schools in the Faculty of Humanities, who had evidence of open access publication. These six researchers were interviewed between November 2020 and January 2021. Interviews were transcribed, de-identified and analysed using thematic analysis. Due to the diversity of HASS research, four types of research output were in the scope for this study: journal articles, books, creative practice research outputs and grey literature. However, this article will only discuss the findings relevant to open access journal articles.

\section{Literature Review}

Previous open access research has explored the perspectives of librarians, researchers and third parties (Xia, 2011, p. 81), this literature review considers just the perspective of researchers. The adoption of open access is known to vary depending on the research discipline (Zhu, 2017), and HASS has a lower overall output of open access than other disciplines (Severin et al., 2020, p. 15). Some of the differences between HASS and the sciences may be contributing factors, such as lower humanities journal subscription prices causing less urgency to increase open access (Suber, 2017). Relevant to the ability to pay for APCs, there is also less funding available for research in the humanities and social sciences (Eve et al., 2020, p. 2). Differences between HASS and the sciences in the adoption of open access emphasises the need to find out more about the perceptions, experiences and barriers encountered by HASS researchers.

Some humanities researchers support the idea of open access, but do not share their work as open access (Eve, 2014, p. 30). This reluctance is caused by multiple barriers. Some researchers have a perception that knowledge should only be shared with readers that can understand it (Eve, 2014, p. 31), and fear that research would be remixed due to less restrictive licensing in open access (Eve, 2014, p. 32). HASS researchers were not sure about the meaning of open access in one study (Creaser et al., 2010, p. 152). Although many humanities researchers are aware of the potential benefits of bigger download numbers and higher citations for open access journal articles (Piwowar et al., 2018, p. 1 ), specific barriers to publishing more open access journal articles exist. 
A lack of engagement with institutional repositories is a barrier specific to green open access, and has been reported across multiple studies of researchers in different disciplines. Institutional repositories are an essential part of sharing journal articles as green open access, but researchers had digital preservation concerns (Kim, 2011, p. 252; Yang \& Li, 2015, p. 14), and copyright concerns (Cooper et al., 2020, p. 26; Kim, 2010, p. 1917; Serrano-Vicente et al., 2016, p. 16; Yang \& Li, 2015, p. 14). Researchers were also unaware that many institutional repositories are indexed by Google Scholar (Yang \& Li, 2015 , p. 14). Some researchers were unsure how to save their journal articles in the institutional repository, and felt this process took too long (Cooper et al., 2020, p. 26; Kim, 2010, pp. 1917-1918; Narayan \& Luca, 2017, pp. 15-16; Serrano-Vicente et al., 2016, p. 16; Yang \& Li, 2015, pp. 14, 16).

Researchers across all disciplines are reliant on publishing in established prestigious journals, as this has the potential to advance their careers, and also contribute towards the ranking of their institutions (Bonaccorso et al., 2014, pp. 6-7; Nicholas et al., 2020, p. 136). This reliance is also evident for HASS researchers (Narayan \& Luca, 2017, pp. 15-16; Narayan et al., 2018, p. 177). Established researchers could be more likely to publish as open access, as they are less reliant on prestigious publishing outlets linked to career advancement (Blankstein \& Wolff-Eisenberg, 2019, pp. 39-40). However, a survey of education researchers found that publishing in open access journals did not adversely affect their career advancement (Coonin \& Younce, 2010, p. 130). This barrier to publishing more open access articles, where researchers are reliant on high prestige subscription journals, provides an insight into the conflicting priorities of researchers.

While researchers express support for the idea of publishing journal articles as open access, open access is sometimes a low priority when choosing a journal to publish in (Nicholas et al., 2020, p. 136; Rodriguez, 2014, p. 608; Xia, 2010, p. 622). In a large multi-disciplinary survey of US faculty, there was strong support for a completely open access system instead of the current publication model. However, open access as a factor in choice of journal was only ranked as important by $40 \%$ of respondents (Blankstein \& WolffEisenberg, 2019, pp. 4-5, 40). This shows how open access is not always a high priority when choosing a journal.

The final barrier preventing researchers across all disciplines from making more articles available as open access was concern about open access 
journals. Some researchers felt that open access journals were of lower quality (Rodriguez, 2014, p. 607), including HASS researchers (Edelmann \& Schoßböck, 2020, p. 10; Tenopir et al., 2017, p. 829). The APC-based gold open access route (where the author pays an Article Processing Charge to publish as open access) is seen by many researchers as unaffordable (Bonaccorso et al., 2014, pp. 6-7), especially in HASS (Cooper et al., 2020, p. 25; Richardson et al., 2019, p. 15; Tenopir et al., 2017, p. 839). Predatory journals are run by opportunistic publishers for profit, and generally have no peer review (Grudniewicz et al., 2019). The misuse of open access by many predatory journals has also caused some HASS researchers to lack trust in open access journals (Narayan \& Luca, 2017, pp. 15-16; Richardson et al., 2019, p. 15). These multiple concerns about open access journals provide an insight into the complexity of feelings towards open access.

The literature review suggested that qualitative methods yielded rich insights of experiences of open access, while many quantitative studies explored intentions rather than behaviour. Data collection methods used in qualitative studies included interviews (Bonaccorso et al., 2014; Kim, 2010; Narayan \& Luca, 2017), focus groups (Collins \& Milloy, 2016; Creaser et al., 2010) and workshops (Edelmann \& Schoßböck, 2020). Many studies which used surveys to explore researcher's perceptions of open access included HASS researchers (Blankstein \& Wolff-Eisenberg, 2019; Coonin \& Younce, 2010; Gross \& Ryan, 2015; Mrva-Montoya et al., 2019; Narayan et al., 2018; Richardson et al., 2019; Rodriguez, 2014; Serrano-Vicente et al., 2016; Yang \& Li, 2015).

\section{Methodology}

The research methodology used was founded on an interpretivist paradigm, where the researcher's role is to explore the 'beliefs, feelings and interpretations of research participants' (see Williamson, 2017, p. 10). Open access publication is a complex system comprised of multiple motivations (economic, altruistic and career), layers of infrastructure (repositories, research management systems and journal publishing systems), and multiple actors (researchers, librarians, funders and publishers). For this reason, an interpretivist paradigm was chosen to explore the uniqueness of each researcher's experience of publishing open access journal articles. 
The specific interpretivist paradigm used was personal constructivism, which is the belief that each individual constructs reality in a different way (see Williamson, 2017, p. 12). The objective of remaining 'open to the realities of participants' (Williamson, 2017, p. 15) influenced the research design. In data collection, the semi-structured interviews used open-ended questions so that the participants could guide the conversation. In data analysis, thematic analysis was used to explore perceptions and experiences from the participant's perspective (Braun \& Clarke, 2019, p. 17; Qu \& Dumay, 2011, p. 246).

Trustworthiness in qualitative research can be strengthened by addressing the criteria of credibility, transferability, dependability and confirmability (Lincoln \& Guba, 1985, p. 300). To address credibility in this research, the technique of triangulation (see Lincoln \& Guba, 1985, p. 305) was applied by researching the participants' publication history of journal articles prior to interviews. This included checking the open access status of each article by using the Unpaywall Simple Query Tool (https://unpaywall.org/products/ simple-query-tool). As the Unpaywall Simple Query Tool uses DOIs to check the open access status of articles, articles without a DOI were checked manually. During in-person interviews, a printed copy of the participant's publication record was used to tailor questions. In some cases, having a visible prompt available helped the participants to recall their publishing experiences.

Transferability was addressed by the use of purposive sampling during recruitment for interviews. By ensuring all participants had experience of open access publishing, the potential for rich data was maximised (see Lincoln \& Guba, 1985, p. 316). While this interpretivist research does not intend to be generalisable, the findings may be transferrable to other research institutions (see Williamson, 2017, p. 15). The availability of the interview transcripts (Quigley, 2021a) addresses the criteria of dependability and confirmability (see Lincoln \& Guba, 1985, pp. 317-319), as this open data can be examined by readers in conjunction with the interview guide (Quigley, 2021b).

\subsection{Data Collection}

Purposive sampling was used to identify experienced HASS researchers within the Faculty of Humanities at Curtin University, who had evidence of 
at least one open access publication in their online institutional researcher profile. This approach maximised the familiarity of participants with open access. All participants were research supervisors, where this role involves mentoring and guiding graduate research students including $\mathrm{PhD}$ candidates. While reviewing researcher profiles online during interview recruitment, HASS researchers who also held journal editorial roles were considered.

An email invitation to participate in an interview was sent to selected researchers using their publicly available Curtin email address. Six participants from across the three schools in Curtin's Faculty of Humanities agreed to a one hour individual interview (two participants from each of the School of Design and the Built Environment; the School of Education; and the School of Media, Creative Arts and Social Inquiry).

The semi-structured interviews used open-ended questions, and the interview guide is available online (Quigley, 2021b). Ethics approval was granted by Curtin University's Human Research Ethics Committee. Prior to interviews, participants gave consent for interviews to be recorded, and for their de-identified interview data being used as quotations in publications and shared as openly available data (Quigley, 2021a). Interview topics included perceptions of open access, and experience of publishing and barriers encountered in publishing journal articles as open access.

Six interviews were conducted between November 2020 and January 2021. The total duration of the interviews was approximately six hours. Individual interview durations ranged from 47 minutes to one hour and 27 minutes, with an average interview duration of one hour. Five interviews were conducted in person in participants' offices at Curtin University, Perth, and one interview was conducted online. All interviews were digitally recorded, and transcribed by the author. The combined word count of transcriptions before deidentification was approximately 42,600 words (100 pages).

\subsection{Data Analysis}

Data analysis used the method of thematic analysis (see Braun \& Clarke, 2006, p. 79), as it is suited to the analysis of research questions about people's 
opinions, perceptions, behaviours and experiences (Braun \& Clarke, 2019, p. 17). Data analysis of the interview data used an inductive approach to generate themes. This reflected the experiences of the participants, rather than deductive thematic analysis which uses a predefined framework (see Clarke et al., 2015, p. 225). The thematic analysis process used the six phases described by Braun and Clarke (2006, p. 87) between February and April 2021.

Using MaxQDA qualitative data analysis software, 466 data segments were added to 312 codes. Four themes were then generated by adding codes to MaxQDA sets. Two of these themes relevant to open access journal articles are discussed in this article - the complex perceptions of open access, and confusion about open access. The other two themes of creativity in engaging with industry, and the devaluing of creative practice outputs are outside the scope of this article. Interview recruitment focused on participants with the research supervisor and journal editorial role perspectives. However, two additional perspectives of funding assessor and global citizen were uncovered during interviews. These perspectives will be explored further in the findings section of this article, as they are relevant to the theme of complex perceptions.

\section{Findings}

The perceptions and experiences of publishing journal articles as open access varied among participants. They ranged from positive perceptions due to reaping the benefits of publishing in APC-based gold journals listed in The Directory of Open Access Journals (https://doaj.org/), to negative perceptions caused by confusion around open access concepts. Almost all of the participants faced multiple barriers to publishing journal articles as open access. The participants' answers to the two research questions on perceptions, experiences and barriers are presented first, followed by the theme of complex perceptions. This theme explores how some participants hold multiple opinions of open access, depending on which perspective they are considering. These perspectives are research supervisor, journal editorial, funding assessor and global citizen. The participants' quotes are used throughout this section, and the six participants are referred to as P1 to P6. The non-identifiable gender-neutral pronoun 'they' is used for participant quotes. 


\subsection{Perceptions and Experiences}

Two of the participants have reaped the benefits of publishing journal articles in DOAJ-listed APC-based gold journals (P2 and P3). They have observed the benefits of open access publishing, including higher citations, impact on industry, and faster dissemination of research findings. While most of the participants were aware that open access journal articles could yield higher citations (P3, P4, P5 and P6), P2 had experienced this: '[open access publisher] give big citations by the way [laughs], citation number's going up' (P2). Another perceived benefit was a broader audience (P1, P4, P5 and P6), and P3 had seen their open access articles cited in industry reports: 'because of the open access they can access it' (P3). The quick turnaround of some APC-based gold journals means that the research students supervised by one of the participants can publish multiple journal articles during their PhD. These DOAJ-indexed journals '[...] reply within two weeks, they've understood the system [...] they will get it published within three months' (P2), thereby meeting P2's goal of 'open access, I just want to get it out there' (P2). These participants (P2 and P3) used a blend of paywalled and open access journals to publish their own research, and the research of the students they supervise:

We just tend to publish in some of the more highly ranked journals, but we also publish in some of these [journal publisher whose journals are DOAJ-listed]. We just mix and match, don't have a particular favouritism [...] (P2)

P5 had published an article in a new diamond open access journal, and felt this journal was 'very well peer-reviewed' (P5). They were confident in submitting to this journal because of the editorial board. These experiences show how some of the participants were comfortable in sharing their HASS research as open access journal articles, and appreciated the benefits of open access.

In contrast, other participants expressed confusion about different aspects of open access such as open access terminology, journal policies for making articles open access, and paying APCs using research funds. Two of the participants (P1 and P5) shared that when reading journal articles, they do not know or notice if they are open access or not. There was confusion over open 
access terminology: 'Gold means what?' (P3), 'So what does green mean?' (P4), 'Isn't the gold one [...] cited more?' (P6). When publishing articles with the intention of making them open access, two participants did not realise there was an APC required until after acceptance (P1 and P4). P4 also found it difficult to navigate journal publisher policies on open access, including embargoes for green open access:

I guess a difficulty is that different publishers have different restrictions and guidelines so you've got to kind of go to the trouble of finding out which ones allow you to openly publish and when if ever. So the complexity of all of that is a disadvantage and is awkward and time-consuming. (P4)

In particular, the experience of complying with a funder policy on open access when publishing an article in an APC-based open access journal was 'quite stressful' for P1, because the article had already been accepted and peer reviewed: 'it's not until you actually engage in the processes of the journal itself that you actually realise the fees involved, you know all of the kind of complexities of it' (P1). P4 and a co-author realised after article acceptance that they would have to pay an APC for open access, and used their own personal money to pay half of the APC rather than withdraw the article.

Further confusion was evident when participants were asked about the use of research funds to pay APCs (P1, P4 and P6). P1 learned from past experience that they should build open access publication costs into future research funding applications:

I was aware that open access was a requirement when I put in the application, I had no idea how expensive it was. So I hadn't included anything like that in the budget. [...] It's obviously made me think with this new one that I'm working on I will build that into the fees [...]. (P1)

However, P4 thought that funders did not yet allow open access publication costs to be included in funding applications: '[...] you should be able to use research funding for author pays publications, but I don't think, they don't allow that yet' (P4). These findings where participants were confused about open access show how some were struggling with the practicalities of making more of their journal articles available as open access. 


\subsection{Barriers}

Numerous barriers limited the participants in publishing open access journal articles including no access to funds for APCs, and limited open access journal options in their research area. Some participants ranked open access as a less-important factor when choosing a journal to submit to, and were suspicious of open access due to predatory journals. Other barriers experienced by participants were a lack of time to find out more about open access, and frustration with the process of adding journal articles to the institutional repository. Four of the participants felt that APC funding would make open access journal article publishing easier (P1, P3, P4 and P6). In particular the tendency is for author pays' (P4) was a barrier to publishing open access journal articles, and P5 was 'sceptical about the quality if you're asking me to pay money' (P5). This finding shows that open access journal publishing via APC-based gold was not an option for some participants.

Two of the participants were restricted to publishing in niche journals (P1 and P5): '[...] it is really the only kind of that level of journal in Australia to do with [research topic]' (P1). These niche subscription journals were also how P1 kept informed with new research: 'it's a very small kind of world but there's a definite cohort of academics a lot of whom I've never actually met [...] But I know of them through journals like this' (P1). One participant saw the journals they publish in as 'that's my place, that's my world' (P5), and were not 'hunting for another outlet' to publish in (P5). This finding shows how specialised research areas restricted the open access options for some participants.

When considering journals to publish in, scope was important:

'It's not usually a point of discussion whether you should look for something open access or not. It's more still related to where I'm likely to get accepted and making sure that what I'm publishing is in line with what that journal specialises in' (P4).

Many participants were positively influenced by the journal editorial board when considering submissions to journals they had not published in before (P1, P5 and P6). This finding shows that the scope was more important for some participants than the open access options of a journal when choosing where to publish. 
Emails from predatory publishers were common for some participants (P4, P5 and P6), and all participants received regular requests to publish from publishers of journals and books. P5 shared an email invite with the author, which was from a journal asking for submissions. Emails like this have caused P5 to be '[...] still terrified of predatory publishing [...] to me the asking to pay is still stuck in the predatory publishing space' (P5). For two other participants, predatory publishers were 'getting more and more sophisticated' (P4); '[...] we have so many journals coming out right now and they're charging you fees. There's some bogus ones and do you go with them or not?' (P6). Using the criteria for assessing journals in Grudniewicz et al. (2019) and 'Think. Check. Submit' (see https://thinkchecksubmit.org/journals/), the author checked the journal submission invite post-interview. The journal was found in the ISSN portal (https://portal.issn.org/), but not in the DOAJ (https://doaj.org/). The journal name is identical to another journal that is listed in the DOAJ, but with a different ISSN number. The journal website presents a list of abstracting and indexing databases is which it claims inclusion. However, the databases named are not abstracting and indexing databases, for example WorldCat is actually a worldwide library catalogue. The open access journal under consideration is therefore likely a predatory journal. This finding shows how predatory publishers have caused misconceptions about paid open access, and are eroding trust in open access for some participants.

Another barrier to publishing more journal articles as open access was a lack of time. When asked what institutional changes would encourage open access, P4 suggested 'guidance and funding', as '[...] academics are increasingly busy. So to go searching for that kind of information, [I] just don't have the time' (P4). For invitations received by email looking for journal submissions, P5 did not have time to check if the opportunity presented was genuine or from a predatory journal: 'And I just think I am too busy to spend half an hour finding out if your journal ... whereas I can feel confident that the journals that I read through the firewall of Curtin are of high calibre' (P5). P1 felt that 'an average academic would not have the time to just sit there and voluntarily read the open access policy' (P1) when discussing the difficulty of complying with funder policies on open access.

Frustration with the process of adding journal articles to the institutional repository was a barrier to green open access. The institutional repository used at Curtin University is DSpace (https://duraspace.org/dspace/), 
however, there is no direct access for researchers to the institutional repository. Instead, the process of adding permitted journal articles as green open access to the institutional repository is via the research output management system, Symplectic Elements (https://www.symplectic.co.uk/ theelementsplatform/). When asked about making journal articles available as green open access, P4 said 'it's kind of too much trouble I suppose' (P4), and found using Elements 'a bit confusing ... and that's one of the reasons I think why I don't do it' (P4). P2 also felt that adding their articles to the institutional repository via Elements should be easier:

'So I sort of started doing that and then it asked me lots of questions and I just can't be bothered. I've actually got a lot to do. It's not that I don't want to help the university but I just feel that should work, that should just work.' (P2).

While P3 also felt that 'the process is a bit tedious', they persisted because they saw adding their journal articles to the institutional repository as 'the opportunity for people to have access to my top-ranked journals. They can easily assess them in space. It will grow my citations. It will grow my reputation' (P3). In addition to frustrations with the institutional repository, there were also misconceptions. During interview, P1 was surprised when the author explained to them that the institutional repository has visibility outside of Curtin University, and is indexed by Google Scholar:

'... not knowing that feels a little bit like you just sticking it in a dusty darkened cave somewhere, rather than for the purposes of building a record rather than it actually being an active searchable repository' (P1).

These findings show that the participants face multiple barriers to making more of their journal articles available as open access.

\subsection{Complex Perceptions}

All participants in this study were research supervisors. In addition, some participants held journal editorial roles, and some were funding assessors. In Australia, a funding assessor uses their research area knowledge to advise funders on funding application approvals (see Australian Research Council, 
2020). Two of the participants referred to developing countries when expressing their perceptions of open access (Px and Py). These participants consider themselves as 'global citizens' who belong to 'multiple, diverse, local and non-local networks' (see United Nations, n.d.). This awareness of being a global citizen is important because of inequities currently built into certain open access models. For example, the requirement to pay an APC to publish an article disadvantages researcher in developing countries (Massarani et al., 2021).

Some participants in this research have complex perceptions about open access relevant to these four perspectives of the research supervisor, journal editorial, funding assessor and global citizen. Two of the participants did not hold a single consistent opinion on open access, but instead held multiple conflicting opinions depending on which perspective they were considering. The participant codes in this section have been renamed as Px, Py and Pz for this theme, because the journal editorial and funding assessor roles could be potentially identifying. In the de-identified transcripts, the quotations relevant to this theme are in a separate section (Quigley, 2021a, p. 69). Each of the four perspectives is explored with support from the participants' quotations, to show how their conflicting opinions on open access influence their behaviour.

\subsubsection{Research Supervisor Perspective}

All participants had experience of the role of research supervisor. One participant felt that publishing too many open access articles was a negative for PhD students:

Again if the student, $\mathrm{PhD}$ student are just publishing on those open access [journals] it will affect their reputation as well. They may not be able to stand out when they go for interview with other researchers. So I have to warn my students, you can go for one or two but not that many (Py)

Py also suggested that PhD students 'can play the game of open access, but not in full' (Py). This shows that some participants are urging caution in publishing open access to the research students they supervise. 


\subsubsection{Journal Editorial Role Perspective}

Journal editorial roles were held by three participants ( $\mathrm{Px}, \mathrm{Py}$ and $\mathrm{Pz})$, and these participants provided insights about open access relevant to these roles. The specific editorial roles are not included in this article, so that participants are not identifiable. While performing an editorial role at an APC-based gold journal, Py discovered that the journal was publishing articles without requesting a review from Py. This discovery caused them to resign from their editorial role as they were concerned about their professional reputation. Following the interview with Py, the author checked the journal in question, again using the criteria in Grudniewicz et al. (2019) and 'Think. Check. Submit' (see https://thinkchecksubmit.org/journals/). While the journal was found in the ISSN portal (https://portal.issn.org/), the journal website does not mention peer review, and copyright is transferred to the publisher on article submission. The journal is not listed in the DOAJ (https://doaj.org/) despite being in existence for a few years, and Py is still listed on the journal website as being an editor despite resigning. The open access journal under consideration is therefore likely a predatory journal.

Py has since taken up an editorial role at a different open access journal (listed in DOAJ). They shared that the journal and its impact factor are 'quite good', and will 'stick with them' in an editorial role (Py). Py considers the payment of APCs as a way to get lower quality articles published 'because if they pay the fees, then [it] can be a bit easier' (Py). Py's interpretation of the practice of submitting to multiple journals of descending prestige, is that researchers are trying to 'manipulate the system' (Py). In addition, Py found that 'some editors [...] may be a bit lenient' in their peer-review of articles in open access journals. This finding shows a perception that some researchers submit low quality articles to open access journals following rejection by big publishers.

Two of the participants (Py and $\mathrm{Pz}$ ) in journal editorial roles received APC waivers as recognition of their contribution to the journal; 'it's a [reason] for joining editorial boards' (Pz). This finding shows how some participants used their APC waivers to publish multiple articles without payment in these APC-based gold journals. 


\subsubsection{Funding Assessor Perspective}

Two participants held the role of a funding assessor (Px and Py). When assessing funding applications where the applicant had previous publications in open access journals, Px felt it would probably not influence their perception of the applicant's research abilities: 'I don't think that should directly impact, if those publications are in the area of what they're going to do, what they're proposing [in a funding application]' (Px). However, another funding assessor felt that a fully open access publication record could put a funding applicant at a disadvantage: 'If you didn't try these top journals, you only go for open access, definitely there'll be problems' (Py). Throughout the interview, Py stated that reputation and prestige were important for journals in their research area.

Px did not support the inclusion of open access publication costs in funding applications they were asked to assess:

'[...] if I get an application where an applicant has requested for open access I will [deny it]. Because if the researcher doesn't have the capability to get published in a regular journal, I don't know what we define as a regular journal, I would personally see those three thousand dollars spent somewhere better.' (Px)

Px and Py were uncertain if open access publication costs are permitted by the funder they assess for: 'I don't think [funder] will pay for an open access fee, I haven't seen it so far' (Px). This shows that some participants who are funding assessors were unaware if the funder they assess for permits open access publication costs in funding applications. Funding applicants could also be at a disadvantage where their publications are mostly in open access journals.

\subsubsection{Global Citizen Perspective}

Relevant to a global citizen perspective, two of the participants were considerate of the inequities of APC-based open access journals, where the onus is on researchers to pay to publish (Px and Py): 
[...] one of the main negatives [of open access publishing] is the way it's going to create a gulf between haves and have nots [...]. Is my capability to pay for open access going to decide what visibility, citations and then promotions I get. That's the main barrier for me. A big no. [...] What about those academics in developing countries who can't pay for that [open access]. It's that ethical dilemma of who does it and how you do it and that's a negative for me. (Px)

However, the same participants saw the benefits of open access for developing countries, such as access to knowledge without having to pay journal subscriptions:

[...] if things are open access they can access it and read and understand it and cite us [...] So we impact the whole wide world, you need to think about the needs of those people, especially from developing countries. So that's how they can access my paper, and understand what I've been doing on that subject, in that area (Py).

Open access journals with APCs were considered by Py as an option for researchers to publish in if they could afford it:

[...] it's a good platform for young researchers to access, or to get into this world. [...] They are not rich in developing countries, the charges are quite high in US dollars [...] They still do it. Why, because they have no other avenues. They go through the traditional way, that's rejection (Py).

These two participants with a global citizen perspective (Px and Py) realised the benefits of open access for research consumers in developing countries, while also being aware that APC-based gold open access was unfair to research producers who cannot afford to pay. To summarise this theme, the complex views of open access in two participants has influenced their open access behaviour.

\section{Discussion}

This section discusses the findings of this research relevant to the research questions about perceptions, experiences and barriers, followed by a discussion of the theme of complex perceptions. Suggestions are made for future research, and the limitations of this study are described. 


\subsection{Perceptions, Experiences and Barriers}

Within this study, many of the participants had negative experiences of open access publishing in journals. P1 was stressed when they realised they would have to pay an APC to meet the open access requirements of their funder, and P4 paid half of an APC from their own money post-submission when they realised the journal charged APCs for open access. Py was uncertain about the rigour and quality of peer review of an open access journal and resigned from their editorial role. P4, P5 and P6 are continually approached by predatory journals via emails, which has caused some of them to erroneously associate predatory journals with genuine open access publishing options. Even within this small study, for researchers who are engaging with open access, these experiences show how the reality of choosing to publish open access journal articles can be difficult.

These experiences suggest an opportunity for research institutions to encourage researchers to check the open access policies of journals before submission, rather than after acceptance. The Sherpa Romeo website at https:// v2.sherpa.ac.uk/romeo/ can be used by researchers to easily check open access policies of journals, and ensure their target journal complies with any open access requirements from their research funder. In this study participants were not directly asked about Sherpa Romeo, but seemed unaware of this resource based on their recounted experiences. The gaps in knowledge of open access even among experienced researchers show how education on open access is vital. In addition to educating research supervisors, any increased engagement with open access could have a positive impact on the students they supervise - the next generation of researchers.

As discussed in the findings section, funding applicants were unsure if they could request open access costs when applying for funding, and funding assessors were uncertain if open access publication costs are permitted by the funder they assess for. While libraries are responsible for open access education, in Australian universities the institution's research office generally provides advice on funding applications Singh Chawla, 2021). This suggests an opportunity for institutions and funders to clearly advise both funding applicants and assessors about the open access publication costs and limits permitted by funders. Potentially this could contribute to the publication of more open access articles, arising from funded research. 
The perceptions of the HASS researchers in this study are similar to those of participants in previous studies. Participants were aware of the benefits of open access such as increased journal article citations (Piwowar et al., 2018, p. 1), and a bigger audience (Adema \& Ferwerda, 2014, p. 137). The barriers encountered by participants in this study to publishing open access also reflect previous studies including no access to funds for APCs (Cooper et al., 2020, p. 25; Richardson et al., 2019, p. 15; Tenopir et al., 2017, p. 839) and limited open access journal options in their research area (Bonaccorso et al., 2014 , p. 6). Further barriers to publishing open access include the low ranking of open access as a factor when choosing a journal to submit to (Nicholas et al., 2020, p. 136; Rodriguez, 2014, p. 608; Xia, 2010, p. 622), and suspicion of open access due to predatory journals (Narayan \& Luca, 2017, pp. 15-16). Participants in this study also had a lack of engagement with the institutional repository, similar to the findings of Cooper et al. (2020, p. 26) and Narayan and Luca (2017, pp. 15-16). An understanding and awareness of barriers that researchers face is key for research institutions, so that these barriers can be acknowledged and addressed.

\subsection{Complex Perceptions}

The inclusion of participants who also held journal editorial roles (Px, Py and $\mathrm{Pz}$ ), enabled exploration of perceptions of open access across different perspectives of the research supervisor, journal editorial, funding assessor and global citizen. This research found that some participants hold concurrent and conflicting opinions on open access depending on their perspective, which influences their level of support for open access. This suggests that maintaining a coherent opinion of open access may be challenging for some researchers, and is dependent on the perspective they are considering. These dissonant opinions show the struggle of trying to attain the incompatible goals set by many research institutions: gain promotion by publishing with high prestige journals; share more journal articles as open access; and engage with and impact industry. Participants who perceive too many publications in open access journals as negative have been influenced by their institution's promotion processes and emphasis on high ranking and high prestige journals. With an awareness of the complexity of opinions that one researcher can hold, research institutions can attempt to address this in their education, resources and services that support open access. 


\subsection{Future Research}

The data collection method of semi-structured interviews generated rich findings for this research, and was suitable for the exploration of perceptions, experiences and barriers. The openly available semi-structured interview guide (Quigley, 2021b) can be used by other research institutions to engage with their HASS research communities, and identify the challenges faced by researchers in publishing their journal articles as open access. The finding that some individual researchers are capable of maintaining multiple conflicting views on open access was surprising. Further work in this area could explore this finding for other institutions, and suggest interventions where open access can be promoted and embedded into academic work practices.

\subsection{Limitations}

This research was undertaken as part of a Master of Information Management by coursework over ten months, which bounded the number of participants and scope. Interview recruitment for this research was time-intensive, with the publication history of over fifty Curtin University researchers in the Faculty of Humanities reviewed for suitability. Twelve invites were sent directly to selected researchers and six accepted. Most interviews did not exceed an hour due to the time constraints of the participants, and all participants were from a single institution.

The study which these findings are based on included multiple types of research outputs (journal articles, books, creative practice research outputs and grey literature). On reflection, this scope was too ambitious to cover within the limitations of a Master of Information Management research project. The wide scope meant that it was not possible to ask all questions of all participants within an hour interview, and questions were prioritised for each participant's main research outputs. Additionally, the insights in this study into different types of open access were limited by participant experience. Only one participant in this study had experience of publishing in a diamond open access journal, and none had experience of publishing in a hybrid open access journal. Most experiences of open access publishing in this study were of APC-based gold open access, and some of green open access. 
Arising from this study, the author is now working on a funded research project with HASS researchers at Curtin University. The reason for this project is to identify ways to increase the visibility of creative practice research outputs such as artworks and creative writing, and is funded by the Curtin Open Knowledge Initiative (https://openknowledge.community/).

\section{Conclusion}

This research found a diversity of behaviours around open access, even within this small group of experienced HASS researchers at a single institution. The complex perceptions of open access expressed by some participants shows that for some researchers, supporting open access is not straightforward. As long as HASS researchers depend on publishing in specific prestigious paywalled journals to advance their careers, they will be limited to APC-based gold and hybrid open access (where they can afford it), and green open access (where permitted by publishers). Any increase in engagement with open access among research supervisors, such as those interviewed in this study, has the potential to influence the next generation of researchers.

The findings of this research are transferable in the form of the following recommendations for research institutions:

- identify local barriers to open access by talking to different communities of researchers

- $\quad$ provide clarity to funding applicants and assessors on when research funding is permitted for open access publication costs, and

- be aware that researcher's perceptions of open access can be complex, depending on if the researcher is considering their perspective as research supervisor, editorial role at journal, funding assessor or global citizen.

The institution in this study now has a greater awareness of the needs of the HASS research community, and momentum to effect change. Two additional projects are already underway to better support the specific open access needs of the HASS researcher community. Libraries and research support services need to work with HASS researchers to identify and overcome barriers 
to open access. Publishing more open access journal articles has the potential to share the diversity of HASS research more widely, and have a positive impact on society.

\section{Data Availability}

The interview guide is openly available from the Zenodo repository as 'HRE 2020-0598 research data: Interview guide' (Quigley, 2021b). The de-identified interview transcripts are openly available from the Zenodo repository as 'HRE 2020-0598 research data: Interview transcripts' (Quigley, 2021a).

\section{Acknowledgements}

This article is based on some of the findings of a Master of Information Management dissertation supervised by Dr Hollie White, School of Media, Creative Arts and Social Inquiry at Curtin University. The author would like to acknowledge the support of Curtin University Library in collaborating on this research project, and the participants for sharing their thoughts and experiences of open access. The author also thanks the Master's dissertation examiners, and Liber Quarterly peer reviewers for their helpful comments that improved this article.

The author acknowledges and respects the traditional owners of the land on which interviews were conducted and this article was written, the Whadjuk people of the Noongar nation in Western Australia.

\section{References}

Adema, J., \& Ferwerda, E. (2014). Publication practices in motion: The benefits of open access publishing for the humanities. In P. Dávidházi (Ed.), New publication cultures in the humanities: Exploring the paradigm shift (pp 131-46). Amsterdam University Press. https://pureportal.coventry.ac.uk/en/publications/ publication-practices-in-motion-the-benefits-of-open-access-publi.

Australian Research Council. (2018). Australian Research Council Profile. Australian Research Council. https://www.arc.gov.au/about-arc/arc-profile. 
Australian Research Council. (2020). How to become an ARC assessor. Australian Research Council. https://www.arc.gov.au/how-become-arc-assessor.

Blankstein, M., \& Wolff-Eisenberg, C. (2019, April 12). Ithaka S+R US faculty survey 2018. Ithaka S+R. https://sr.ithaka.org/wp-content/uploads/2019/03/SR-ReportUS-Faculty-Survey-2018-04122019.pdf.

Bonaccorso, E., Bozhankova, R., Cadena, C., Čapská, V., Czerniewicz, L., Emmett, A., Oludayo, F., Glukhova, N., Greenberg, M., Hladnik, M., Grillet, M., Indrawan, M., Kapović, M., Kleiner, Y., Łaziński, M., Loyola, R., Menon, S., Morales, L., Ocampo, C., ... Rosenblum, B. (2014). Bottlenecks in the open-access system: Voices from around the globe. Journal of Librarianship and Scholarly Communication, 2(2), Article eP1126. https://doi.org/10.7710/2162-3309.1126.

Bosman, J., Frantsvåg, J. E., Kramer, B., Langlais, P.-C., \& Proudman, V. (2021). OA diamond journals study. Part 1: findings. Zenodo.

Braun, V., \& Clarke, V. (2006). Using thematic analysis in psychology. Qualitative Research in Psychology, 3(2), 77-101. https://doi.org/10.1191/1478088706qp063oa.

Braun, V., \& Clarke, V. (2019). Answers to frequently asked questions about thematic analysis. The University of Auckland. https://cdn.auckland.ac.nz/assets/psych/ about/our-research/documents/Answers $\% 20$ to $\% 20$ frequently $\% 20$ asked $\% 20$ questions \%20about\%20thematic\%20analysis\%20April\%202019.pdf.

Clarke, V., Braun, V., \& Hayfield, N. (2015). Thematic analysis. In Qualitative psychology: A practical guide to research methods (3rd ed., pp. 222-248). SAGE Publications.

Collins, E., \& Milloy, C. (2016). OAPEN-UK final report: A five-year study into open access monograph publishing in the humanities and social sciences. Jisc. https:/ /oapen. fra1.digitaloceanspaces.com/7a65d73f1087444d80807833a320fa36.pdf.

Coonin, B., \& Younce, L. M. (2010). Publishing in open access education journals: The authors' perspectives. Behavioral E Social Sciences Librarian, 29(2), 118-132. https://doi.org/10.1080/01639261003742181.

Cooper, D., Mahoney, C., Springer, R., Behra, R., Beilin, I., Burak, G., Burri, M., Carns, P. M., Champagne, A., Cobine, C., Cole, H., Courtney, A., Donlon, A., Ecklund, A., Evelyn, S., Fanning, D., Figueroa, P., Friedland, N., González, L., ... Witte, S. (2020, September 9). Supporting research in languages and literature. Ithaka S+R. https://doi. org $/ 10.18665 /$ sr.313810.

Creaser, C., Fry, J., Greenwood, H., Oppenheim, C., Probets, S., Spezi, V., \& White, S. (2010). Authors' awareness and attitudes toward open access repositories. New Review of Academic Librarianship, 16(sup1), 145-161. https://doi.org/10.1080/1361453 3.2010.518851.

Edelmann, N., \& Schoßböck, J. (2020). Open access perceptions, strategies, and digital literacies: A case study of a scholarly-led journal. Publications, 8(3):44. https://doi.org/10.3390/publications8030044. 
Eve, M. P. (2014). Open access and the humanities: Contexts, controversies and the future. Cambridge University Press. https://doi.org/10.1017/CBO9781316161012.

Eve, M. P., Vega, P. C., \& Edwards, C. (2020). Lessons from the Open Library of Humanities. LIBER Quarterly, 30(1), 1-18. https:/ / doi.org/10.18352/lq.10327.

Gross, J., \& Ryan, J. C. (2015). Landscapes of research: Perceptions of open access (OA) publishing in the arts and humanities. Publications, 3(2), 65-88. https://doi.org/10.3390/publications3020065.

Grudniewicz, A., Moher, D., Cobey, K. D., Bryson, G. L., Cukier, S., Allen, K., Ardern, C., Balcom, L., Barros, T., Berger, M., Ciro, J. B., Cugusi, L., Donaldson, M. R., Egger, M., Graham, I. D., Hodgkinson, M., Khan, K. M., Mabizela, M., Manca, A., ... Lalu, M. M. (2019). Predatory journals: No definition, no defence. Nature, 576(7786), 210-212. https://doi.org/10.1038/d41586-019-03759-y.

Kim, J. (2010). Faculty self-archiving: Motivations and barriers. Journal of the American Society for Information Science and Technology, 61(9), 1909-1922. https://doi.org/10.1002/asi.21336.

Kim, J. (2011). Motivations of faculty self-archiving in institutional repositories. The Journal of Academic Librarianship, 37(3), 246-254. https://doi.org/10.1016/j. acalib.2011.02.017.

Lincoln, Y. S., \& Guba, E. G. (1985). Naturalistic inquiry. Sage Publications. http://archive.org/details/naturalisticinqu00linc.

Massarani, L., Rodrigues, M., Longmene Kaze, B., Badr, H., \& Mazouzi, R. (2021, May 10). Open access 'excludes' developing world scientists. Sci Dev Net. https:/ / www.scidev. net/global/features/open-access-excludes-developing-world-scientists/.

Mrva-Montoya, A., Luca, E. J., \& Boateng, H. (2019). Understanding

Australian academic authors in the humanities and social sciences: Their publishing experiences, values, and perspectives. Journal of Scholarly Publishing, 51(1), 38-62. https://doi.org/10.3138/jsp.51.1.03.

Narayan, B., \& Luca, E. J. (2017). Issues and challenges in researchers' adoption of open access and institutional repositories: A contextual study of a university repository. Information Research, 22(4), paper rails 1608. https://opus.lib.uts.edu.au/ handle/10453/121438.

Narayan, B., Luca, E. J., Tiffen, B., England, A., Booth, M., \& Boateng, H. (2018). Scholarly communication practices in humanities and social sciences: A study of researchers' attitudes and awareness of open access. Open Information Science, 2(1), 168-180. https://doi.org/10.1515/opis-2018-0013.

Nicholas, D., Watkinson, A., Abrizah, A., Rodríguez-Bravo, B., Boukacem-Zeghmouri, C., Xu, J., Świgoń, M., \& Herman, E. (2020). Does the scholarly communication system satisfy the beliefs and aspirations of new researchers? Summarizing the Harbingers research. Learned Publishing, 33(2), 132-141. https://doi.org/10.1002/leap.1284. 
Piwowar, H., Priem, J., Larivière, V., Alperin, J. P., Matthias, L., Norlander, B., Farley, A., West, J., \& Haustein, S. (2018). The state of OA: A large-scale analysis of the prevalence and impact of open access articles. PeerJ, 6, e4375. https://doi.org/10.7717/peerj. 4375 .

Qu, S. Q., \& Dumay, J. (2011). The qualitative research interview. Qualitative Research in Accounting \& Management, 8(3), 238-264. https://doi. org/10.1108/11766091111162070.

Quigley, N. (2021a). HRE 2020-0598 research data: Interview transcripts (Version 3) [Data set]. Zenodo. https://doi.org/10.5281/zenodo.4774447.

Quigley, N. (2021b). HRE 2020-0598 research data: Interview guide (Version 1) [Interview guide]. Zenodo. https://doi.org/10.5281/zenodo.4774475.

Richardson, J. W., McLeod, S., \& Hurst, T. (2019). Perceptions of educational leadership faculty regarding open access publishing. International Journal of Education Policy and Leadership, 15(5). https://doi.org/10.22230/ijepl.2019v15n5a817.

Rodriguez, J. E. (2014). Awareness and attitudes about open access publishing: A glance at generational differences. Journal of Academic Librarianship, 40(6), 604-610. https://doi.org/10.1016/j.acalib.2014.07.013.

Serrano-Vicente, R., Melero, R., \& Abadal, E. (2016). Open access awareness and perceptions in an institutional landscape. The Journal of Academic Librarianship, 42(5), 595-603. https://doi.org/10.1016/j.acalib.2016.07.002.

Severin, A., Egger, M., Eve, M. P., \& Hürlimann, D. (2020). Discipline-specific open access publishing practices and barriers to change: An evidence-based review. F1000Research, 7:1925. https://doi.org/10.12688/f1000research.17328.2.

Singh Chawla, D. (2021, October 25). The blurred line of responsibility between research offices and libraries. Nature Index. https://www.natureindex.com/news-blog/ blurred-line-responsibility-between-research-offices-libraries.

Suber, P. (2012).Economics. In P. Suber (Ed.), Open Access (1st ed.). MIT Press. https://doi.org/10.7551/mitpress/9286.003.0009

Suber, P. (2017, June 8). Why is open access moving so slowly in the humanities? Blog of the APA. https://blog.apaonline.org/2017/06/08/ open-access-in-the-humanities-part-2/.

Suber, P. (2019). Varieties. In P. Suber (Ed.), Open Access (1st ed.). MIT Press. https://doi.org/10.7551/mitpress/9286.003.0005.

Tenopir, C., Dalton, E. D., Christian, L., Jones, M. K., McCabe, M., Smith, M., \& Fish, A. (2017). Imagining a gold open access future: Attitudes, behaviors, and funding scenarios among authors of academic scholarship. College E Research Libraries, 78(6), 824-843. https://doi.org/10.5860/crl.78.6.824. 
United Nations. (n.d.). Global citizenship. United Nations. https://www.un.org/en/ academic-impact/global-citizenship.

Williamson, K. (2017). Research concepts. In K. Williamson \& G. Johanson (Eds.), Research methods: Information, systems, and contexts (2nd ed., pp. 3-25). Chandos Publishing.

Xia, J. (2010). A longitudinal study of scholars attitudes and behaviors toward openaccess journal publishing. Journal of the American Society for Information Science and Technology, 61(3), 615-624. https://doi.org/10.1002/asi.21283.

Xia, J. (2011). An anthropological emic-etic perspective on open access practices. Journal of Documentation, 67(1), 75-94. https://doi.org/10.1108/00220411111105461.

Yang, Z., \& Li, Y. (2015). University faculty awareness and attitudes towards open access publishing and the institutional repository: A case study. Journal of Librarianship and Scholarly Communication, 3(1), eP1210. https://doi.org/10.7710/2162-3309.1210.

Zhu, Y. (2017). Who support open access publishing? Gender, discipline, seniority and other factors associated with academics' OA practice. Scientometrics, 111(2), 557-579. https://doi.org/10.1007/s11192-017-2316-z. 